\title{
Study on quality control of modern agricultural supply chain based on food safety
}

\author{
YAO Yuchen ${ }^{1, a}$,Jiang Fangtao ${ }^{2, b}$ and Zhang $\mathrm{Li}^{3, \mathrm{c}}$ \\ ${ }^{1}$ Hohai University, Jinling Institute of Technology.Nanjing, China \\ 2 Jinling Institute of Technology.Nanjing, China \\ ${ }^{3}$ Jinling Institute of Technology. Nanjing, China \\ a yuchen5111@sina.com, b jft5078@sina.com, ${ }^{c}$ zhangli@jit.edu.cn
}

Key words: Food safety; Agricultural supply chain; Supermarket ; Quality control

\begin{abstract}
This paper analyzed the particularity of agricultural supply chain, established a quality control model of modern agricultural supply chain. Erect supermarket distribution center as the key point of quality control, implement a one-stop quality testing by setting testing standards, testing process, testing equipments, testing personnel and testing methods, so that quality control procedures can be simplified, and the food safety of modern agricultural supply chain can be ameliorated.
\end{abstract}

\section{Introduction}

Recently, food safety incidents of agricultural products like Sanlu milk powder scandal, Sudan red, Hogwash oil, emerge in an endless stream. With a strict food supervision system, Europe cannot avoid this, such as "Horsemeat" scandal. Food safety of agricultural products has much to do with the nationals' health and the steady and coordinated development of society. The repeated problems show that there is much room for further improvement in agricultural supply chain, and the modern agricultural supply chain, as an important development direction, has a bright future for greater development, and it is easier to implement its quality and safety control, compared with other types of agricultural products supply chain. Improving the quality control of the modern agricultural products supply chain is of much benefit to improve the quality of agricultural products, reduce the environmental pollution and create a safe food environment.

\section{The Related Studies Home and Abroad}

The majority of foreign developed countries have the specialized agencies for food safety supervision, and make special laws which provide that the food industries have the duty to ensure the food safety, and the perfect food recall mechanisms. Boehlje and Schrader ${ }^{[1]}$ held that the management of food chain should focus on the coordination between manufacturers, suppliers and processors so as to enhance the overall efficiency. ChriStian ${ }^{[2]}$ analyzed that the mutual cooperation between the enterprises in food chain has played a big role in European pork, beef and grain supply, and discussed the construction of the food quality and safety direction and its traceability system. Ahumada ${ }^{[3]}$ believed that the design and operation of edible agricultural product supply chain will be subjected to stricter regulations and monitoring, because food safety is closed related to nationals' public health.

China's food safety regulation involves many departments, but they have not achieved high efficiencies, for the executive branches concerned do not define the clear functional areas, make their functions decentralized and overlapped. Pan Qingli (2012) ${ }^{[4]}$, in the perspective of the supply chain in agricultural products processing enterprises, discussed the potential food safety hazards in the supply chain. Shi Sheng ${ }^{[5]}$ thought that enterprises and farmers didn't have complete and symmetrical information about each other, so entrusted agencies could help stimulate farmers to engage in the production of safe agricultural products. 
By scanning the study findings home and abroad, it is found that there are a lot of studies about the food safety supervision and agricultural products supply chain, but lack of the detailed studies in the perspective of food safety, about the supermarket chains ---the leading agricultural products supply chain.

\section{Problems in quality control of modern agricultural supply chain}

(1) Lack of sound food safety supervision systems, and there being functions decentralized and overlapped among the supervision departments.

China's food safety supervision system is a rather intricate network, instead of a completely separate parallel structure, or an independent but partly intersected network. When the functions need to be decentralized, all the departments rush headlong into action for profits. However, when the cooperation is needed, they take department protectionism and act on their own. Thus various consequences come in a row: lack of specialized persons liable for food safety supervision, the supervision departments existing in name only and shirking their responsibilities on the food safety problems, low efficiency in food supervision work, food safety problems emerging in an endless stream.

(2) Its complicated structure, long cycle and large amount of agricultural products circulation in modern agricultural products supply chain bring many difficulties to food supervision.

If food regulation covers too broad, even the whole process of the agricultural supply chain, it will greatly increase the difficulties and workloads of food safety inspection. The complicated modern supply chain of agricultural products consists of upstream farmers and production bases, midstream agricultural products processing enterprises, wholesale markets and supermarket distribution centers, and downstream supermarkets and terminal consumers. So large numbers of nodes, huge agricultural product turnovers, and high turnover frequency, bring great difficulties to achieve all-round and whole-process control.

(3) Through food safety detection techniques, agricultural chemicals have such a great variety that it is very difficult to achieve a comprehensive detection to ensure food safety.

Now, a lot of fruits and vegetables on the market are not maturing and stored naturally, many farmers ripen strawberry, mango, cherry, tomato, grape, cucumber and other fruits and vegetables by using ripener, and sellers preserve the agricultural products by using such chemicals as "formaldehyde", "formalin" etc. The agricultural chemicals like ripeners can do great harm to human body, and if improperly used, will cause food poisoning, even threaten people's life safety. As there are a great variety of detecting substances, different agricultural products need to be detected by different food safety detection means. So to establish a rapid, simple, sensitive, accurate detection system for food safety is an effective method to guarantee people's health and prevent food-borne diseases.

(4) Many food safety problems have not been brought under control before found, and there is no related prevention mechanism to nip in the bud.

Nowadays, the related supervision departments did not trace the root of the problems, call the responsible parties to account, and punish them, until the grave consequences were exposed by the mass media. Then the legislature will make mends to make or perfect the relevant laws. Therefore, a sound mechanism is needed to prevent food safety problems.

\section{Quality control model of modern agricultural supply chain.}

In modern agricultural supply chain, erect supermarket distribution centers as the key point for a one-stop quality detection. Internal quality control can be improved by quality system certification. By establishing testing standards, testing processes, testing equipments, testing personnel and testing methods, the quality control procedures can be simplified, and the food safety of modern agricultural supply chain can also be improved. Figure 1 is a quality control model of modern agricultural supply chain. 


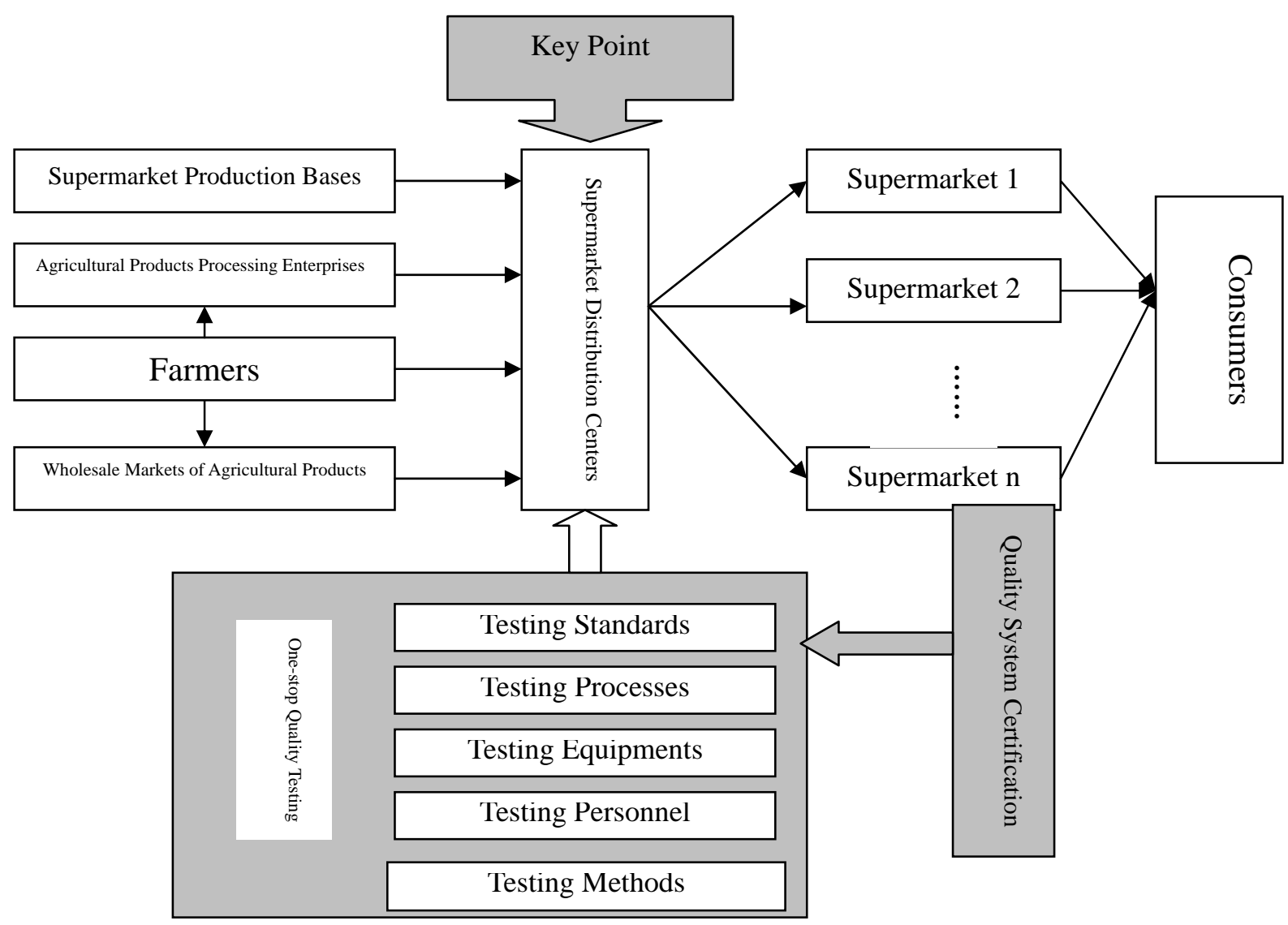

Figure 1 Quality control model of modern agricultural supply chain.

\section{Conclusions and suggestions}

(1) To re-establish the food safety regulation authority and cooperation mechanism.

In present days, China's food supervision departments are in the charge of the Ministry of health, State Administration for Industry and Commerce, General Administration of Quality Supervision, Inspection and Quarantine of the PRC. And Food Hygiene Law of PRC only entitles the public health administrative department to management authority, and is unable to support the supervision system of different departments. So the top task is to re-establish the authority and cooperation mechanism of relevant enforcement bodies, to divide the respective authorities among all the departments, to establish a principle of cooperation between the administrative departments in the form of written laws, to centralize the functions of food safety supervision, to make the duties clearer, and to improve the supervision efficiency by setting up an efficient and authoritative coordination mechanism.

(2) To establish key quality control nodes which center on supermarkets.

The supermarkets have the relatively good detection abilities. They also have great advantages in equipments, personnel, and techniques. Therefore, they can bring the quality of agricultural products under control, by allocating the detection equipment and personnel, establishing perfect technical specifications, detection records and the quality control system of the detecting process, and carrying out incoming inspection. In addition, the supermarkets have dependable identification system for agricultural products traceability, which favors controlling the quality of agricultural products at the source.

(3) Compel supermarkets to make certification of agricultural products through Quality and Safety Certification System, and purchase and use fast and reliable agricultural product quality detection equipment. 
Supermarkets should adhere to selling the pollution-free agricultural products, strive to develop green food and organic food, and promote the coordinative development of pollution-free agricultural products, green food and organic food. Agricultural products quality and safety certification is an important technical resource to promote the construction of agricultural modernization, a chief safeguard to guarantee qualified agricultural products in supermarkets, and an effective way to implement the brand strategy of agricultural products. At present, many supermarkets can only detect agricultural products by rapid qualitative means rather than by quantitative analysis, which cause great difficulties to guide production and trace their sources. As a result, supermarkets should purchase advanced quality testing equipments, and strictly detect various agricultural products quality by using kinds of detection techniques.

(4) Encourage key nodes in supply chain like supermarkets to connect with one another according to integration management mode, and build up a more stable product supply and demand up to quantity and quality standards.

By encouraging the use of contract production pattern between farmers and supermarkets, the supermarkets can obtain safe and high quality agricultural products. It can help contract farmers to get stable and high income, and protect agricultural eco environment as well. Besides, it can promote the integrated use of modern technology in agricultural production to ensure the quality of agricultural products and the environmental safety of their places of origin, and alleviate and prevent agricultural spatial pollution.

\section{References}

[1] Boehlje. M. L. F Schrader, “The Industria1ization of Agricu1ture: Questions of Coordination” In The Industrialization of Agriculture, eds. J. S. Royer and R. C. Rogers, 3-26. Great Britain: The Ipswich Book Company, 1988.

[2] Christian Fischer, Monika Hartmann. Factors influencing contmcaml choice and sustainable relationships in European agri-food supply chains[J]. European Review of Agricultural Economics. 2007(36):541-569

[3] Ahumada O, Villalobos J R. Application of planning models in the agri-food supply chain: Areview[J]. European Journal of Operational Research. 2009(59). 1-20

[4] Pan Qingli. Chinese agricultural supply chain management research Under the background of food safety [J]. agricultural economy, 2012, (11).

[5] Shi Sheng. Research on information transmission efficiency of Food safety traceability system -Research based on agricultural supply chain [D]. Huazhong Agricultural University, 2008, (5). 